\title{
DATA-DATA YANG DIGUNAKAN DALAM PROSES ASUHAN KEPERAWATAN DAN METODE PENGUMPULAN DATA
}

\author{
Helena Gultom
}

\author{
Email : helenaagultom@gmail.com
}

\section{Latar Belakang}

Proses pengkajian merupakan tahap awal dari proses keperawatan yang dilakukan secara sistematis dengan mengumpulkan data individu secara komperhensif terkait aspek biologis, psikologis, sosial, maupun spiritual.Tahap pengkajian merupakan dasar utama dalam memberikan asuhan keperawatan sesuai dengan kebutuhan individu. Oleh karena itu, pengkajian yang akurat, lengkap, sesuai dengan kenyataan, kebenaran data sangat penting dalam merumuskan suatu diagnosa keperawatan dan memberikan pelayanan keperawatan sesuai dengan respon individu, sebagaimana yang telah ditentukan dalam standar praktik keperawatan dari ANA (American Nursing Association). Perawat melaksanakan tugas sebagai pemberi asuhan keperawatan berwenang melakukan pengkajian keperawatan holistik (Undang-Undang RI Nomor 38 Tahun 2014 Tentang Keperawatan, 2015:3). Fase dari pengkajia meliputi: pengumpulan data, analisis data, pengelompokan data dan dokumentasi data (Haryanto, 2008).Pengumpulan data adalah kegiatan perawat dalam mengumpulkan informasi yang aktual tentang klien. Pengumpulan data ini dilakukan untuk mengidentifikasi dan mendapatkan data yang penting dan akurat tentang klien (Asmadi, 2008). Dokumentasi pengkajian keperawatan adalah catatan perawat yang berisi informasi dari pasien, membuat data dasar tentang pasien, dan membuat catatan tentang respons kesehatan klien.

\section{Metode}

Jenis metode yang digunakan dalam penelitian ini adalah literatur review .Data yang diperoleh dari pengumpulan bahas pustaka tentang jenis dan sumber pengkajian dalam keperawatan Metode ini memuat langkah-langkah dalam pengumpulan data agar akurat dan jelas untuk meneggakan diagnose keperawatan dan melakukan intervensi yang benar. 


\section{Hasil}

Berdasarkan hasil literature review, pengkajian merupakan dasar utama dalam asuhan keperawatan yang dilakukan dengan mengumpulkan data tentang status kesehatan pasien secara sistematis, menyeluruh, akurat, lengkap, sesuai dengan kebenaran .Peran perawat dalam melakukan pengkajian keperawatan kebutuhan pasien berdasarkan aspek bio,psiko,sosio,spiritual didapatkan dua tema yaitu tema 1 adalah melaksanakan pengkajian awal dan tema 2 ialah melaksanakan pengkajian lanjutan. Tema 3 adalah Pelaksanaan pengkajian secara holistik dilakukan oleh perawat dalam waktu-waktu tertentu Data tersebut diperoleh melaluianamnesa, observasi, dan pemeriksaanpenunjang dan kemudian didokumetasikan.Data adalah suatu informasi yang harus dikumpulkan untuk keperluan dalam menganalisis dan merumuskan diagnosa keperawatan.

Fokus pengumpulan data dalam Nursalam (2004) meliputi:

a) status kesehatan sebelumnya dan sekarang

b) pola koping sebelumnya dan sekarang

c) fungsi status sebelumnya dan sekarang

d) respon terhadap terapi medis dan tindakan keperawatan

Menurut ((Kozier \& Erb, 2004) teknik (metode) utama yang dapat digunakan dalam pengumpulan data adalah wawancara, observasi, dan pemeriksaan fisik serta diagnostik. 


\section{Pembahasan}

\section{Pengumpulan Data}

Pengumpulan data merupakan proses mendapat informasi tentang kondisi kesehatan dari klien. Dalam hal ini kesehatan komunitas. Proses pengumpulan data harus dilakukan secara sistematik dan terus menerus untuk mendapatkan data atau informasi yang signifikan yang menggambarkan kondisi kesehatan komunitas.

a. Tipe data

Data dapat berupa data subjektif atau data objektif. Data subjektif biasa dikaitkan sebagai keluhan. Di komunitas, data subjektif biasa terkait dengan keluhan komunitas, misalnya terkait lingkungan yang tidak nyaman secara fisik dan psikologis, perasaan tertekan, perasaan ketakutan, dan sebagainya. Data subjektif meliputi, sensasi komunitas terkait dengan perasaan, nilai-nilai, keyakinan, sikap dan persepsi terhadap status kesehatan atau situasi kehidupannya. Data objektif biasanya berkaitan dengan tanda-tanda yang dapat dideteksi dengan pengamatan, dapat diukur atau diperiksa dengan menggunakan standar. Informasi atau data diperoleh dengan menggunakan indera penglihatan, pendengaran, dan sentuhan/peraba, yang biasanya dilakukan melalui metode observasi dan pemeriksaan.

b. Sumber data

Tujuh sumber-sumber data dalam pengkajian (Kozier \& Erb, 2009), yaitu:

a) Klien merupakan sumber utama dan perawat bisa mendapatkan informasi yang sebenarnya mengenai masalah kesehatan klien. Bila perawat mendapatkan data atau informasi yang berbeda dari keadaan fisik atau perilaku klien, maka perawat harus memberitahukan data tersebut kepada sumber lain.

b) Orang terdekat merupakan orang lain yang pasti mengetahi kondisi klien dengan baik. Orang terdekat bisa memberikan informasi tentang klien sebagai informasi tambahan. Orang terdekat misalnya orangtua, suami atau istri, anak atau teman pasien. Apabila klien ada gangguan atau keterbatasan dalam berkomunikasi ataupun kesadaran yang menurun. Hal ini dapat terjadi pada 
klien anak-anak, dimana informasi diperoleh dari ibu atau yang menjaga anak selama di rumah sakit.

c) Tenaga kesehatan merupakan orang- orang yang berhubungan dengan klien, dalam melakukan tindakan, mengevaluasi, dan mencatat hasil pada status klien. Perawat, pekerja sosial, dan fisioterapi.

d) Catatan medis merupakan sumber kesehatan klien sekarang dan masa lalu dan pola penyakit. Catatan ini dapat memberikan perawat informasi mengenai perilaku koping klien, praktik kesehatan, dan penyakit sebelumnya.

e) Laporan dan catatan lain yang dapat memberikan informasi kesehatan klien. Data laboratorium dapat dapat menjadi sumber informasi bagi seorang perawat selama pengkajian keperawatan dan pemeriksaan kesehatan fisik. Laporan dan catatan lain sebagai contoh, laporan sebuah lembaga sosial yang pada kondisi kehidupan klien atau laporan lembaga perawatan kesehatan rumah pada koping klien di rumah yang dapat membantu perawat.

f) Literatur keperawatan yang berkaitan seperti jurnal profesional dan teks referensi, dapat menjadi sumber informasi tambahan untuk database.

\section{Metode Pengumpulan Data}

Ada tiga metode yang digunakan dalam pengumpulan data pada tahap pengkajian, yaitu : komunikasi, observasi, dan pemeriksaan fisik.

\section{1) Komunikasi}

Semua interaksi perawat dengan klien adalah berdasarkan komunikasi terapeutik yaitu suatu teknik dimana usaha mengajak klien dan keluarga untuk bertukar pikiran dan perasaan.

\section{2) Observasi}

Tahap kedua pada pengumpulan data adalah dengan observasi yaitu mengamati perilaku dan keadaan klien untuk memperoleh data tentang masalah kesehatan dan keperawatan klien. Kegiatan observasi meliputi : 2S HFT (Sight, Smell, Hearing, Feeling, dan Taste). Kegiatan tersebut mencakup aspek fisik, mental, sosial, dan spiritual. Sight meliputi kelainan fisik, 
perdarahan, terbakar, menangis dan sebagainya. Smell meliputi alkohol, darah, faeces, medicine, urine, dsb. Hearing meliputi tekanan darah, batuk, menangis, ekspresi nyeri, heart rate dan ritme, sedangkan Taste meliputi sentuhan.

3) Pemeriksaan fisik

Pemeriksaan atau pengkajian fisik dalam keperawatan dipergunakan untuk memperoleh data obyektif dari riwayat keperawatan klien yang dilaksanakan bersama dengan wawancara. Tujuan dari pengkajian fisik didalam keperawatan adalah untuk menentukan status kesehatan klien, mengidentifikasi masalah kesehatan dan mengambil data dasar untuk menentukan rencana tindakan keperawatan.

\section{Kesimpulan}

Proses pengkajian merupakan tahap awal dari proses keperawatan yang dilakukan dengan cara mengumpulkan data secara sistematis.Pengkajian harus dilakukan dengan lengkap ,akurat sesuai kebenaran dan menyeluruh.Data adalah suatu informasi yang harus dikumpulkan untuk keperluan dalam menganalisis dan merumuskan diagnose keperawatan. Data terdiri dari sumber data,tipe data penggelompokan data dan verifikasi data.

\section{Daftar Pustaka}

Trinitas Bawalu . (2019) .Data- Data dan Teknik yang Digunakan Pada Pengkajian Dalam Proses Keperawatan

Ns. Wahyu Widagdo .M.Kep ,Sp.Kom.(2016).Keperawatan Keluarga dan Komunitas .Jakarta Seltan .Pusdik SDM Kesehatan

Syahbana Ali ,dkk. (2019).Profesional Health Journal.Perat Perawat Dalam Melakukan Pengkajian Kebutuhan Pasien Berdasarkan Aspek Biologis ,Psikologis ,Sosiologis,Spiritual Di Ruang Rawat Inap .Vol.1.No 1. Hal 21-26 
Rutami ,Setiawan .(2012) . Pelaksanaan Proses Keperawatan Di Ruang Rawat Inap RSUP H. Adam Malik Medan

Nurhayati Muhuddin .(2013). “Faktor-Faktor Yang Berhubungan Dengan Kinerja Perawat Dalam Pelaksanaan Asuhan Keperawatan Di Ruang Rawat Inap Private Care Center RSUP Dr Wahidin Sudirohusodo Makassar ". Skripsi .Fakultas Kedokteran .Program Studi Ilmu Keperawatn .Universitas Hasanuddin

Angganis F, A. dkk. (2012). Hubungan Sikap Perawat Dengan Pendokumentasian Asuhan Keperawatan di Ruang Rawat Inap Umum Rs. Dr Sitanala di Tangerang. Jurnal keperawatan, Volume 1, hal. 12.

Ali, H. Zaidin. (2016). Dasar-Dasar Dokumentasi Keperawatan. Jakarta: EGC

Dinarti, Yuli mulyanti. (2017). Dokumentasi Keperawatan. Kementrian Kesehatan RI

Simamora, R. H. (2019). Development of Guidelines for Applying appropriate Patient Identification to Achieve Patient Safety Goal

INC2019 12th International Nursing Conference. 2019.10455 - 455 (1 pages)

UCI(KEPA) : I410-ECN-0101-2019-512-001224337

Simamora. R. H. (2008) The correlation of ward chief's giving direction and command and the performance of on-duty nurses at Jember dr. Subandi general hospital inpatient wards. jurnal Administrasi dan Kebijakan Kesehatan, (https://fkm.unair.ac.id/jurnal-administr) 
